\title{
A healthy body, a healthy mind: long-term impact of diet on mood and cognitive function
}

\author{
Peter J. Rogers \\ Department of Experimental Psychology, University of Bristol, Bristol BS8 1TN, UK
}

\begin{abstract}
Certain dietary risk factors for physical ill health are also risk factors for depression and cognitive impairment. Although cholesterol lowering has been suggested to increase vulnerability to depression, there is better support for an alternative hypothesis that intake of $n-3$ long-chain polyunsaturated fatty acids can affect mood (and aggression). Possible mechanisms for such effects include modification of neuronal cell membrane fluidity and consequent impact on neurotransmitter function. Stronger evidence exists concerning a role for diet in influencing cognitive impairment and cognitive decline in older age, in particular through its impact on vascular disease. For example, cognitive impairment is associated with atherosclerosis, type 2 diabetes and hypertension, and findings from a broad range of studies show significant relationships between cognitive function and intakes of various nutrients, including long-chain polyunsaturated fatty acids, antioxidant vitamins, and folate and vitamin $\mathrm{B}_{12}$. Further support is provided by data on nutrient status and cognitive function. Almost all this evidence, however, comes from epidemiological and correlational studies. Given the problem of separating cause and effect from such evidence, and the fact that cognitive impairment and cognitive decline (and depression) are very likely to be significant factors contributing to the consumption of a poor diet, greater emphasis should now be placed on conducting intervention studies. An efficient approach to this problem could be to include assessments of mood and cognitive function as outcome measures in studies designed primarily to investigate the impact of dietary interventions on markers of physical health.
\end{abstract}

Dietary risk factors: Cognitive function: Depression: Vascular disease

The theme of the present review is that dietary risk factors for physical (ill) health are also often risk factors for mental (ill) health. Perhaps the most obvious example of this relationship is the effects of chronic undernutrition in early or later life. Other examples are the effects of Fe deficiency, and the possible role played by various dietary constituents in influencing vulnerability to depression and cognitive decline. It is these latter aspects of psychological well-being that will be considered. In the case of cognitive decline an important and rather direct link with physical well-being is the impact of diet on vascular health. Cognitive impairment is a major cause of disability in old age, and depression is also a very significant contributor to human ill health. Indeed, it has been predicted that by 2020 depression will rank second as a contributor to the global burden of disease, measured in terms of 'disability-adjusted life years' (Murray \& Lopez, 1996). Other predictions are that IHD and cerebrovascular disease will rank one and four respectively. Clearly identifying the modifiable risk factors, including dietary risk factors, for these causes of human morbidity is therefore a very important task.

\section{Diet and depression}

\section{Carbohydrate and protein effects on brain serotonin}

Wurtman et al. (1981) proposed that the balance of protein and carbohydrate consumed in a meal can influence brain serotonin (5-hydoxytryptamine) neurotransmission by altering the availability of tryptophan for uptake into the brain. Tryptophan is the precursor amino acid of serotonin and, paradoxically, high carbohydrate intake tends to increase brain uptake of tryptophan. Serotonin is involved in the modulation of various aspects of mood and behaviour, including depression, aggression, impulsivity, sleep and appetite (Maes et al. 1996; Rogers, 1995), and one

\footnotetext{
Abbreviations: DHA, docosahexaenoic acid; LCPUFA, long-chain polyunsaturated fatty acids; MMSE, mini-mental state examination; SENECA, Survey in Europe of Nutrition and the Elderly, a Concerted Action.

Corresponding author: Dr Peter J. Rogers, fax +44 117 9288588, email Peter.Rogers@bristol.ac.uk
} 
prediction from this theory is that meals high in protein will increase alertness. A second prediction is that carbohydraterich snacks and meals will, fairly acutely, relieve depressed mood, especially exemplified in 'carbohydrate-craving obesity', premenstrual syndrome and seasonal affective disorder, conditions which it is argued are characterised by depressed mood and a craving for and increased intake of high-carbohydrate foods (Wurtman \& Wurtman, 1989). This prediction has led to the suggestion that the increased carbohydrate intake constitutes self-medication to relieve the depression. Although there is some evidence to support these claims, other results suggest that the variations in protein and carbohydrate intake achieved by eating real foods are insufficient to significantly affect brain serotonergic function (for example, see Teff et al. 1989a,b), and a majority of the relevant studies show that even very large differences in carbohydrate and protein intake fail to produce reliable behavioural effects (Spring et al. 1987; Rogers, 1995).

\section{Cholesterol and cholesterol-lowering treatments}

The possibility of an unexpected relationship between cholesterol and psychological well-being was highlighted by the meta-analysis by Muldoon et al. (1990) of drug and diet cholesterol-lowering trials, which indicated that lowering cholesterol increased 'non-illness' mortality. That is, while mortality from CHD tended to be decreased in men receiving interventions to reduce serum cholesterol, there was a significant increase in deaths from accidents, suicide or violence. Not surprisingly, the publication of this paper stimulated much interest and further work.

Subsequent analyses of intervention trials and cohort studies, however, only partly confirmed the existence of these adverse effects of low serum cholesterol (for reviews see Muldoon et al. 1993; Hibbeln \& Salem 1995; Wardle, 1995; Hibbeln, 1999). For example, there tends to be a ' $\mathrm{J}$ '-shaped relationship between all-cause mortality and cholesterol, but the contention that low-cholesterol groups suffer higher rates of suicide and accidental death, and are more depressed, aggressive and hostile was not generally supported. Also, the well-established positive association between CHD and both depression and type A behaviour pattern (of which hostility is an important component) is difficult to reconcile with low or lowered cholesterol being a risk factor for suicide and violent behaviour (Wardle, 1995). Nevertheless, in a small study (Ploeckinger et al. 1996) postpartum depression scores were found to be worse in women showing the largest decreases in serum cholesterol after delivery. Furthermore, in intervention studies dietary manipulation of serum cholesterol in cynomolgus monkeys was found to significantly affect their social behaviour; low cholesterol being associated with more-aggressive lessaffiliative behaviour, and also lower cerebrospinal fluid concentrations of 5-hydroxyindoleacetic acid, a metabolite of serotonin (Kaplan et al. 1991, 1994).

The latter observations provide support for the most popular account of how serum cholesterol could affect mood and behaviour, and in turn increase an individual's vulnerability to suicide, and violent and accidental death. It has been proposed that lowered cholesterol levels cause changes in cell membrane composition and fluidity, among the effects of which are decreased brain serotonergic neurotransmission (for example, see Engelberg, 1992; Kaplan et al. 1994). However, this suggested link between cholesterol, serotonin and behaviour remains largely speculative. In the case of the study by Ploeckinger $e t$ al. (1996) the rate of turnover of cholesterol in cellular membranes is too slow to explain the relationship between sudden changes in serum cholesterol and mood. Indeed, taking into account recent results from new randomised controlled trials, the balance of evidence on the behavioural consequences of low cholesterol and cholesterol lowering in human subjects is reassuring. Although these trials found some significant changes in cognitive performance (see p. 140), there were no adverse effects of cholesterollowering dietary and drug treatments on mood, including depression, anger and anxiety (Wardle et al. 1996, 2000; Polet et al. 1998; Muldoon et al. 2000).

\section{Long-chain polyunsaturated fatty acids}

Phospholipids and cholesterol are major components of cellular membranes. As indicated earlier, the fatty acid composition of these lipids affects membrane function due to alterations in membrane fluidity and interactions with membrane proteins, and is susceptible to dietary influences. In brain cellular membranes the most abundant fatty acids are arachidonic acid (20:4n-6), adrenic acid (22:4n-6) and docosahexaenoic acid (22:6n-3; DHA), with particularly high concentrations occurring in the membranes of neuronal synapses and the retina (Linder, 1991; British Nutrition Foundation, 1992; Litman \& Mitchell, 1996). Accordingly, long-chain polyunsaturated fatty acids (LCPUFA) intakes may affect mood and behaviour by fairly direct effects on neural function. Such a mechanism has been suggested in relation to observations ranging from associations between diet and depression (as discussed here) and between breastfeeding and infant mental and psychomotor development.

Hibbeln and his colleagues (Hibbeln \& Salem, 1995; Hibbeln et al. 1997; Hibbeln, 1999) have proposed that a deficiency of $n-3$ LCPUFA is an important factor underlying increased vulnerability to depression, and hostile and aggressive behaviour. In part, this hypothesis is based on the broad observations that there appear to be lower rates of depression in societies where $n-3$ LCPUFA intakes are high, and that there has been a marked rise in lifetime prevalence of depression in North America and many European countries over the last 100 years concomitant with an increase in the proportion of $n-6$ LCPUFA relative to $n-3$ LCPUFA consumed in the diet. The latter is due largely to the currently high intake of vegetable oils (e.g. safflower, sunflower and maize oils) and low intake of fish oils. Furthermore, from an evolutionary perspective this high $n-6$ LCPUFA : $n$-3 LCPUFA value probably represents a very substantial change from the values in the diets of early man (even assuming minimal intake of fish). A further important argument is that adverse psychological changes associated with some cholesterol-lowering dietary and drug treatments are due to effects on intakes and tissue concentrations of LCPUFA, and not to a reduction of cholesterol levels. This outcome is because, for example, cholesterol-lowering diets 
that emphasise substitution of LCPUFA for saturated fatty acids usually also markedly alter the $n-6$ LCPUFA : $n-3$ LCPUFA consumed. More specific evidence for a relationship between mood and LCPUFA status comes from clinical studies. Adams et al. (1996), for instance, found significant correlations $(P<0.05-P<0.01)$ between the severity of depression in moderately- to severely-depressed patients and blood measures of phospholipid fatty acid composition, all indicating worse depression in patients with a higher n-6 LCPUFA: $n$-3 LCPUFA (e.g. higher arachidonic acid : eicosapentaenoic acid (20:5n-3)). Furthermore, other studies have revealed significant differences $(P<0.05-P=0.004)$ in serum or erythrocyte fatty acid composition between depressed patients and age-matched control participants. These differences consisted mainly of lower $n-3$ LCPUFA concentrations in samples from the depressed patients (Maes et al. 1996; Edwards et al. 1998; Peet et al. 1998).

There are also a small number of relevant intervention studies. Hamazaki et al. (1996) found that double-blind supplementation with DHA-rich fish oil for 3 months reduced verbal aggression and scores on a questionnaire measure of hostility in stressed participants. These participants were assumed to be stressed because they were tested during their university examinations period. No psychological effects of DHA supplementation were found in a replication of this study conducted at a time when no important examinations were scheduled (Hamazaki et al. 1998). A clinical intervention study showed that bipolar depressives benefited significantly, as measured by longer remission of their illness, from supplementation with large amounts (total of $9.6 \mathrm{~g} / \mathrm{d}$ ) of eicosapentaenoic acid and DHA over 4 months (Stoll et al. 1999). And finally, although a recent dietary trial (Polet et al. 1998; Wardle et al. 2000) found no adverse effects on mood related to cholesterol lowering (see earlier discussion), there was evidence consistent with an effect of LCPUFA intakes on mood. The participants were moderately hypercholesterolaemic, but were not clinically depressed, and sub-groups of these participants completed mood diaries before and at 2, 6 and 12 weeks after starting their dietary treatment. Compared with the 'dysphoric/tense' mood scores of a waiting-list control group, scores on the same mood factor were increased following the introduction of a low-fat relatively-high- $n-6$ LCPUFA diet, but decreased on a 'Mediterranean diet' that included the instruction to increase consumption of oily fish (these two dietary treatments reduced serum LDL-cholesterol to a similar extent) (Polet et al. 1998). Taken together, these results from both correlational and intervention studies provide preliminary support for the proposal that $n$-3 LCPUFA can have significant effects on mood. However, confirmation of the benefits for psychological well-being of increasing $n-3$ LCPUFA intakes requires substantial further research, especially larger-scale intervention studies.

One of the suggested mechanisms underlying a link between LCPUFA intakes and depression, hostility etc. is again an alteration of brain serotonergic function (Hibbeln et al. 1997; Hibbeln, 1999). Some support for this mechanism comes from a study of forty-five healthy individuals that found highly-significant positive correlations
$(P<0.005)$ between plasma total LCPUFA and cerebrospinal fluid concentrations of the serotonin metabolite 5hydroxyindoleacetic acid and also the dopamine metabolite homovanillic acid (Hibbeln et al. 1997). However, although levels of these neurotransmitter metabolites were not significantly correlated with serum total cholesterol, their relationship with the supposedly critical $n-6$ LCPUFA : $n$ - 3 LCPUFA value was not reported. In further studies plasma DHA concentrations were found to be negatively correlated $(P<0.005)$ with cerebrospinal fluid 5-hydroxyindoleacetic acid and homovanillic acid concentrations in a group of early-onset alcoholics and a group of violent individuals, but in healthy controls the same variables were positively correlated $(P<0 \cdot 005$; Hibbeln et al. 1998a,b). These results are difficult to interpret, especially without information on LCPUFA intakes, but clearly they provide at best equivocal support for an effect of LCPUFA on neurotransmitter function. Thus, other mechanisms, such as immuneneuroendocrine effects, might better explain any impact of n-3 LCPUFA on mood (Hibbeln, 1999).

\section{Folate}

Young (1993) reviews evidence showing an association between low folate and depression, which he proposes may be in part mediated by alterations in brain $S$-adenosylmethionine and serotonin levels. $S$-Adenosylmethionine has an antidepressant action and has been shown to increase brain serotonin turnover (and it can also affect membrane fluidity and receptor sensitivity); crucially folate can affect levels of methionine (see p. 139), the immediate precursor of $S$-adenosylmethionine. In addition, there is some tentative support from placebo-controlled trials for a therapeutic benefit of folate in the treatment of depression (for example, see Godfrey et al. 1990; for review, see Alpert \& Fava, 1997).

Depression is also linked to cerebrovascular disease (Rao, 2000). Partly, this co-morbidity is explained by damage to frontal and subcortical brain areas following cerebral ischaemia. In turn, diet potentially plays a very significant role in the aetiology of cerebrovascular disease, and this role and its implications for cognitive function will now be discussed.

\section{Diet and cognitive decline}

\section{Atherosclerosis, type 2 diabetes, hypertension and obesity}

An important link between diet and cognitive decline in older age is suggested by the association of cognitive impairment with atherosclerosis, type 2 diabetes and hypertension. The aetiologies of these disease states are complex and partly overlapping, but dietary factors are involved to at least a significant extent. Thus, before reviewing some of the specific evidence suggesting an impact of diet on cognitive function in the elderly, it is worth noting why atherosclerosis, type 2 diabetes and hypertension increase the risk of cognitive impairment.

Of major importance is the greater risk of cerebral ischaemia and stroke associated with atherosclerosis and thrombosis (for example, see Gale et al. 1996). Recent data 
also show a significant correlation between atherosclerosis and an increased risk of Alzheimer's disease (as well as an increased risk of vascular dementia; Hofman et al. 1997). There is, furthermore, a well-established link between the prevalence of dementia and the presence of one or more E4 alleles of the apolipoprotein E gene (Rubinsztein, 1995; Hofman et al. 1997; also, see Bondi et al. 1995). The apolipoprotein $\mathrm{E}$ gene produces apolipoprotein $\mathrm{E}$ which is involved in, among other things, transport of cholesterol in the blood and neuronal repair (Rubinsztein, 1995). An implication of this finding that there is an association between the apolipoprotein E4 genotype and dementia is that potentially protective interventions, including dietary intervention, could be targeted for high-risk groups (see Dixon et al. 1997).

Among the mechanisms that Stewart \& Liolitsa (1999) identified as possibly contributing to an association between type 2 diabetes and cognitive impairment and dementia are atherosclerosis, hypo- and hyperglycaemia, and effects on acetylcholine neurotransmitter function. Kalmijn et al. (1995) came to similar conclusions regarding results from the Zutphen Elderly Study. Importantly, their analyses showed evidence of cognitive impairment associated with impaired glucose intolerance and hyperinsulinaemia in nondiabetic participants, as well as an association between cognitive impairment and the presence of type 2 diabetes.

In relation to hypertension, there is evidence that elevated blood pressure in mid-life is associated with an increased risk of dementia 15-20 years later (Stewart, 1999). Current cognitive impairment in the elderly tends to be associated with low blood pressure. Stewart (1999) concludes that 'Arteriosclerotic pathology can be assumed to be an important mediating factor in the association between hypertension and dementia'. The evidence on hypertension and later dementia is therefore sufficiently strong to indicate potentially significant benefits of preventative intervention, although dietary interventions (reduction of $\mathrm{NaCl}$ intake) might be relatively ineffective compared with drug treatments. Given the apparent time lag in the impact of hypertension, presumably such treatment would need to be started in middle age to be effective. Anti-hypertensive medication administered to elderly patients was found not to benefit cognitive function (Prince et al. 1996). Finally, it is of course the case that type 2 diabetes, insulin resistance and hyperinsulinaemia, dyslipdaemia, atherosclerosis, hypertension and stroke are all complications of obesity (Shaper et al. 1997; Dhurandhar \& Atkinson, 1999). Consequently, avoidance of obesity, as well as having widespread benefits for physical health, can be expected to reduce the risk of cognitive decline in later life. Sleep disturbance due to nocturnal apnoeic episodes associated with obesity may also be a more immediate cause of poorer cognitive performance (Prinz, 1995).

\section{Long-chain polyunsaturated fatty acids}

There is a considerable body of evidence linking the relative intakes of $n-6$ and $n$-3 LCPUFA and/or intakes of $n-3$ LCPUFA (especially eicosapentaenoic acid and DHA) with CHD. Among the proposed mechanisms underlying the protective effect of higher intakes of $n-3$ LCPUFA are effects on thrombosis, postprandial triacylglycerol levels, inflammatory responses, blood pressure and insulin sensitivity (Kinsella et al. 1990; British Nutrition Foundation, 1999). Accordingly, LCPUFA intakes can also be expected to have an impact on cognitive function, especially in relation to cognitive impairment and cognitive decline in older age. Some support for this proposal comes from data from two longitudinal studies of risk factors for chronic diseases carried out in The Netherlands. The Zutphen Elderly Study revealed a association between cognitive impairment (defined as mini-mental state examination (MMSE) score $\leq 25$; Folstein et al. 1975) and higher linoleic acid (18:2n-6) intake (Kalmijn et al. 1997a). This result remained significant $(P=0 \cdot 04)$ after adjustment for several confounding factors, including age, education and smoking. Estimates of intakes of $n-3$ polyunsaturated fatty acids were not significantly related to cognitive function, although high fish consumption tended to be inversely associated $(P=0.09)$ with cognitive impairment and cognitive decline over a 3-year period. Kalmijn et al. (1997a) specifically interpreted their results as supporting a role for diet in the development of cognitive impairment through its impact on vascular disease, the result for linoleic acid being consistent with the view that the relative intake of $n-6$ and $n-3$ polyunsaturated fatty acid is a significant dietary factor in the development of atherosclerosis and thrombosis (Kinsella et al. 1990). These findings were confirmed, at least in part, by data from the much larger Rotterdam Study, that showed an inverse relationship between fish consumption and risk of dementia $(P=0.03)$, and particularly Alzheimer's disease $(P<0.005$; Kalmijn et al. 1997b). Also, it is worth noting that these studies possibly underestimate any impact of fatty acids, because of the difficulty of accurately measuring fatty acid intakes.

\section{Antioxidant vitamins}

Many authors have proposed that cognitive impairment might be prevented or significantly delayed by increased intake of antioxidants in the diet, such as vitamins $\mathrm{C}$ and $\mathrm{E}$ and $\beta$-carotene (for example, see Kalmijn et al. 1997a; Lethem \& Orrell, 1997). This view is based on various lines of evidence. For example, biochemical and physiological studies implicate oxidative damage to the central nervous system microvasculature in the aetiology of neurodegenerative diseases, including Alzheimer's disease (Richardson, 1993; Thomas et al. 1996), and oxidative modification of LDL is thought to be a critical component of the atherosclerotic process (Witztum, 1994; Frei et al. 1996). In addition, vitamin $E$ could be expected to influence the development of atherosclerosis via effects on immune function (Meydani, 1998).

More directly, epidemiological and correlational studies have demonstrated significant relationships between cognitive function in the elderly and antioxidant nutrient intake or status. Gale et al. (1996), for example, reported an association between cognitive impairment and a low vitamin $\mathrm{C}$ intake and a low plasma ascorbic acid level, and also between cognitive impairment and increased risk from ischaemic stroke. These authors concluded that vitamin $\mathrm{C}$ status may influence cognitive function in elderly people 
through an effect on atherogenesis. Another study of elderly people (Ortega et al. 1997) found significant relationships $(P<0.05)$ between cognitive function, measured using the MMSE, and about ten dietary intake variables. Included among these variables were intakes of vitamin $\mathrm{C}$, $\beta$-carotene, folate and $\mathrm{Fe}$ (positive associations), and intakes of monounsaturated fatty acids, saturated fatty acids and cholesterol (negative associations) (also, see La Rue et al. 1997). On the other hand, Kalmijn et al. (1997a) found no significant relationships between intakes of the potential antioxidants vitamins $\mathrm{C}$ and $\mathrm{E}, \beta$-carotene and various flavonoids, and either cognitive impairment or cognitive decline in elderly men, again assessed using the MMSE. Similar results were obtained from the Rotterdam Study, except for a significant association $(P=0.04)$ between impaired cognitive function (MMSE $\leq 25)$ and lower intake of $\beta$-carotene (Jama et al. 1996).

Other studies have investigated cognitive function and vitamin status. The Survey in Europe of Nutrition and the Elderly, a Concerted Action (SENECA), for example, found significant, though weak, correlations between MMSE scores and plasma levels of carotenoids $(P<0 \cdot 01)$ and vitamin E ( $P<0.001$; Haller et al. 1996). Another study also found that low plasma total carotenoid levels were associated with poor cognitive performance (Berr et al. 1998). However, in a large multi-ethnic sample of elderly Americans poor memory performance was found to be significantly related $(P=0.025)$ only to serum levels of vitamin $E$, and not to levels of vitamins $A$ and $C$, and Se and $\beta$-carotene (Perkins et al. 1999). These results were obtained after statistical adjustment for confounding factors in the latter studies (Berr et al. 1998; Perkins et al. 1999), but this procedure was not done in the analysis of the SENECA data of Haller et al. 1996 (also, see Perrig et al. 1997; Schmidt et al. 1998).

This somewhat equivocal support for a beneficial impact of dietary antioxidant intakes in relation to cognitive function has not been greatly added to by two recent intervention studies. Smith et al. $(1999,2000)$ conducted a 12-month randomised double-blind placebo-controlled study of antioxidant vitamin supplementation (vitamins $\mathrm{C}$ and $E$ and $\beta$-carotene) in the elderly (60-80 years). No significant effects of supplementation on mood or cognitive function were observed. Significant positive relationships $(P<0.05-P<0.01)$ were found for changes in plasma ascorbic acid level and changes in mood, and changes on some measures of cognitive function (cognitive failures questionnaire and new adult reading test); however, this outcome occurred mainly for participants showing low mood and cognitive function scores at baseline, and it was independent of which group they were assigned to (placebo or vitamin supplementation). Also no such relationship was observed for computerised measures of cognitive performance. The latter were mostly tests of fluid abilities (in contrast to the new adult reading test), which can be expected to be most responsive to nutritional effects. On the other hand, Sano et al. (1997) reported that vitamin E supplementation significantly slowed progression of Alzheimer's disease (also, see Morris et al. 1998). This result has attracted considerable attention, and further trials have been started, although the relevance of the result to normal nutrition is unclear, since a very high dose of vitamin E was used (over 100 times the US recommended dietary allowance). Furthermore, the outcome depended on adjustment for pre-supplementation MMSE scores, which differed significantly between the supplemented and placebo groups.

\section{Folate, vitamin $B_{6}$ and vitamin $B_{12}$}

An elevated plasma level of homocysteine is an independent risk factor for atherosclerosis in the coronary, cerebral and peripheral arteries (Ueland \& Refsum, 1989; Homocysteine Lowering Trialists' Collaboration, 1998), and therefore provides another potential mechanism underlying the association between atherosclerosis and cognitive impairment. Homocysteine is a metabolite of methionine, and vitamins $\mathrm{B}_{6}$ and $\mathrm{B}_{12}$ and folate are cofactors for enzymes, such as cystathionine $\beta$-synthase, which use homocysteine as a substrate (Linder, 1991). Vitamin $\mathrm{B}_{6}$ is a cofactor for cystathionine $\beta$-synthase which catalyses the formation of cystathionine from homocysteine and serine, whereas vitamin $\mathrm{B}_{12}$ and folate are involved in the recycling of homocysteine back to methionine. Absence or deficiency of cystathionine $\beta$-synthase leads to the excretion of large amounts of homocystine, the dimer of homocysteine, in the urine. Untreated, this condition (homocystinuria) results in severe vascular disease, growth and developmental abnormalities, and early death. Heterozygous cystathionine $\beta$-synthase deficiency occurs in $0 \cdot 3-1 \%$ of the general population, and is also associated with markedly increased risk of vascular disease (Ueland \& Refsum, 1989; Clarke et al. 1991). Among several other factors contributing to elevated plasma homocysteine are relative deficiencies of vitamins $\mathrm{B}_{6}$ and $\mathrm{B}_{12}$ and folate, especially in combination with a high-protein diet (Linder, 1991). Furthermore, high homocysteine levels and, for example, vitamin $B_{12}$ deficiency, are relatively common in the elderly population (Stabler et al. 1997).

In a group of middle-aged to elderly men, higher plasma concentrations of vitamin $\mathrm{B}_{12} \quad(P=0.04)$ and folate $(P=0.003)$, and lower plasma concentrations of homocysteine $(P<0 \cdot 001)$ were found to be associated with better spatial copying skills, whereas performance on two tests of memory (backward digit span and incidental recall) was positively correlated $(P<0 \cdot 05)$ with vitamin $\mathrm{B}_{6}$ plasma concentration (Riggs et al. 1996). Ortega et al. (1997) also found a positive association between cognitive function and folate intake, but not with intakes of vitamins $B_{6}$ and $B_{12}$. The SENECA study (Haller et al. 1996) found significant $(P<0 \cdot 01)$ but weak correlations between plasma folate and plasma vitamin $\mathrm{B}_{12}$ level and better cognitive function. Some similar findings were also reported in earlier studies (for review, see Rosenberg \& Miller, 1992). In the general population vitamin supplementation can substantially reduce plasma homocysteine levels. For example, a metaanalysis of randomised trials revealed significant effects of folate supplementation with an additional effect of vitamin $\mathrm{B}_{12}$, but not of vitamin $\mathrm{B}_{6}$. It was concluded that these results have important implications for lowering the risk of 
vascular disease (Homocysteine Lowering Trialists' Collaboration, 1998), and therefore possibly for cognitive function and the amelioration of cognitive decline.

In addition to the mechanisms described earlier, other mechanisms linking vitamin status, homocysteine levels and cognitive function (and mood) have been suggested. For example, homocysteine is a precursor of the excitotoxic amino acids cysteine and homocysteic acid, and therefore could contribute to neurodegeneration independently of atherosclerosis. This possible mechanism is consistent with the conclusion of Riggs et al. (1996) that the association involving homocysteine and cognitive function in their study appeared not to be explained by the presence of vascular disease. Similarly, in a group of depressed elderly subjects, homocysteine levels were found to be higher in those with vascular disease, but homocysteine only correlated significantly $(P=0.03)$ with poorer cognitive function in individuals without vascular disease (Bell et al. 1992). Plasma homocysteine levels were not significantly related to cognitive impairment or cognitive decline in the Rotterdam Study (Kalmijn et al. 1999).

\section{Cholesterol and cholesterol lowering}

At least two correlational studies have reported significant relationships between cognitive performance and cholesterol levels. Taken together, the results suggested worse performance on tasks demanding a high rate of information processing, but better performance on tests of 'crystallized' intelligence, at lower cholesterol levels (Benton, 1995; Muldoon et al. 1997). Such a relationship with information processing speed could conceivably contribute to higher accident rates among low-cholesterol groups. However, although some possible confounding factors were controlled for (age and level of education) in one of these studies (Muldoon et al. 1997), it is of course possible that a crucial factor escaped notice. Dieting to lose weight, for example, reduces serum cholesterol (for example, see Golay et al. 1996; Lean et al. 1997) and is associated with impaired cognitive function, but the poorer performance (on speed of information processing tasks) appears not to be due to the nutritional consequences of food restriction (Green \& Rogers, 1995). On the other hand, significant adverse effects on cognitive performance of cholesterol lowering have recently been reported from two intervention studies. These studies are complementary in that one study used a dietary treatment (Wardle et al. 2000) and the other study used a drug treatment (Muldoon et al. 2000) in order to achieve cholesterol lowering. Both studies showed that the cholesterol-lowering treatments retarded improvement of performance with repeated testing on the tasks.

At first sight these observations appear to contradict the predicted relationship between impaired cognitive function and atherosclerosis risk factors (which include raised serum LDL-cholesterol level). However, these studies (Benton, 1995; Muldoon et al. 1997, 2000; Wardle et al. 2000) investigated generally healthy, mostly young to middle-aged subjects, for whom vascular disease, for example, was probably a relatively insignificant current factor affecting their performance. For older individuals there is evidence that cholesterol is indeed positively related to cognitive impairment. For instance, elevated levels of LDLcholesterol were found to markedly increase the risk of dementia with stroke, but not Alzheimer's disease, in elderly participants (mean age 75 years; Moroney et al. 1999). Furthermore, in the Rotterdam Study there were significant associations between risk of vascular dementia and total fat $(P=0.02)$ and saturated fat $(P=0.01)$ intakes (Kalmijn et al. 1997b).

\section{Conclusions}

Taken together, the findings reviewed here suggest that certain dietary components can influence risk of depression, and risk of cognitive impairment and cognitive decline. Evidence for the latter is somewhat more compelling, and points strongly to the involvement of cerebrovascular disease and associations with atherosclerosis, type 2 diabetes and hypertension. Nevertheless, almost all this evidence comes from correlational studies. Most of these studies are of high quality, have large data sets, and many make adjustments for potential confounding factors such as age, education and smoking (and sometimes for factors such as history of heart disease, which is less appropriate given the important contribution of vascular disease to both heart disease and cognitive impairment), but they need to be complemented by substantial intervention studies. Separating cause and effect is crucial because, as well as being partly interrelated themselves, depression and poor cognitive function are very likely to be significant factors contributing to the consumption of a poor diet. An efficient approach to this problem could be to include assessments of mood and cognitive function as outcome measures in studies designed primarily to investigate the impact of dietary interventions on markers of physical health. Such studies will, however, need to be long term (several years) if the expected benefit is a slowing of cognitive decline, rather than an improvement in absolute levels of performance.

\section{References}

Adams PB, Lawson S, Sanigorski A \& Sinclair AJ (1996) Arachidonic acid to eicosapentaenoic acid ratio in blood correlates positively with clinical symptoms of depression. Lipids 31, Suppl., S157-S161.

Alpert JE \& Fava M (1997) Nutrition and depression: The role of folate. Nutrition Reviews 55, 145-149.

Bell IR, Edman JS, Selhub J, Morrow FD, Marby DW, Kayne HL \& Cole JO (1992) Plasma homocysteine in vascular disease and in nonvascular dementia of depressed elderly people. Acta Psychiatrica Scandinavica 86, 386-390.

Benton D (1995) Do low cholesterol levels slow mental processing? Psychosomatic Medicine 57, 50-53.

Berr C, Richard MJ, Roussel AM \& Bonithon-Kopp C (1998) Systemic oxidative stress and cognitive performance in the population-based EVA study. Free Radical Biology and Medicine 24, 1202-1208.

Bondi MW, Salmon DP, Monsch AU, Galasko D, Butters N, Klauber MR, Thal LJ \& Saitoh T (1995) Episodic memory changes are associated with APOE-epsilon 4 allele in nondemented older adults. Neurology 45, 2203-2206.

British Nutrition Foundation (1992) Unsaturated Fatty Acids: Nutritional and Physiological Significance. London: Chapman \& Hall. 
British Nutrition Foundation (1999) n-3 Fatty Acids and Health. London: British Nutrition Foundation.

Clarke R, Daly L, Robinson K, Naughten E, Cahalane S, Fowler B \& Graham I (1991) Hyperhomocysteinemia: An independent risk factor for vascular disease. New England Journal of Medicine 324, 1149-1155.

Dhurandhar NV \& Atkinson RL (1999) Complications of obesity. In Encyclopedia of Human Nutrition, vol. 3, pp. 1460-1466 [MJ Sadler, JJ Strain and B Caballero, editors]. London: Academic Press.

Dixon LB, Shannon BM, Tershakovec AM, Bennett MJ, Coates PM \& Cortner JA (1997) Effects of family history of heart disease, apolipoprotein E phenotype, and lipoprotein(a) on the response of children's plasma lipids to change in dietary lipids. American Journal of Clinical Nutrition 66, 1207-1217.

Edwards R, Peet M, Shay J \& Horrobin D (1998) Omega-3 polyunsaturated fatty acid levels in the diet and in red blood cell membranes of depressed patients. Journal of Affective Disorders 48, 149-155.

Engelberg H (1992) Low serum cholesterol and suicide. Lancet 339, 727-729.

Folstein MF, Folstein SE \& McHugh PR (1975) "Mini-Mental State": a practical method for grading the cognitive state of patients for the clinician. Journal of Psychiatric Research 12, 189-198.

Frei B, Keaney JF, Retsky KL \& Chen K (1996) Vitamins C and E and LDL oxidation. Vitamins and Hormones 52, 1-34.

Gale CR, Martyn CN \& Cooper C (1996) Cognitive impairment and mortality in a cohort of elderly people. British Medical Journal 312, 608-611.

Godfrey PSA, Toone BK, Carney MWP, Flynn TG, Bottiglieri T, Laundy M, Chanarin I \& Reynolds EH (1990) Enhancement of recovery from psychiatric illness by methylfolate. Lancet 336, 392-395.

Golay A, Allaz A-F, Morel Y, de Tonnac N, Tankova S \& Reaven G (1996) Similar weight loss with low- or highcarbohydrate diets. American Journal of Clinical Nutrition $\mathbf{6 3}$, 174-178.

Green MW \& Rogers PJ (1995) Impaired cognitive function in dieters during dieting. Psychological Medicine 25, 1003-1010.

Haller J, Weggemans RM, Ferry M \& Guigoz Y (1996) Mental health: minimental state examination and geriatric depression scores of elderly Europeans in the SENECA study of 1993. European Journal of Clinical Nutrition 50, Suppl. 2, S112-S116.

Hamazaki T, Sawazaki S, Itomura M, Asaoka E, Nagao Y, Nishimura N, Yazawa K, Kuwamori T \& Kobayashi M (1996) The effect of docosahexaenoic acid on aggression in young adults: A placebo-controlled double-blind study. Journal of Clinical Investigation 97, 1129-1134.

Hamazaki T, Sawazaki S, Nagao Y, Kuwamori T, Yazawa K, Mizushima Y \& Kobayashi M (1998) Docosahexaenoic acid does not affect aggression of normal volunteers under nonstressful conditions. A randomized, placebo-controlled, double-blind study. Lipids 33, 663-667.

Hibbeln JR (1999) Long-chain polyunsaturated fatty acids in depression and related conditions. In Phospholipid Spectrum Disorder in Psychiatry, pp. 195-210 [M Peet, I Glen and DF Horrobin, editors]. Carnforth, Lancs.: Marius Press.

Hibbeln JR, Linnoila M, Umhau JC, Rawlings R, George DT \& Salem N (1998a) Essential fatty acids predict metabolites of serotonin and dopamine in cerebrospinal fluid among healthy control subjects, and early- and late-onset alcoholics. Biological Psychiatry 44, 235-242.

Hibbeln JR \& Salem N (1995) Dietary polyunsaturated fatty acids and depression: when cholesterol does not satisfy. American Journal of Clinical Nutrition 62, 1-9.
Hibbeln JR, Umhau JC, George DT \& Salem N (1997) Do polyunsaturates predict hostility and depression? World Review of Nutrition and Dietetics 82, 175-186.

Hibbeln JR, Umhau JC, Linnoila M, George DT, Ragan PW, Shoaf SE, Vaughan MR, Rawlings R \& Salem N (1998b) A replication study of violent and nonviolent subjects: Cerebrospinal fluid metabolites of serotonin and dopamine are predicted by plasma essential fatty acids. Biological Psychiatry 44, 243-249.

Hofman A, Ott A, Breteler MMB, Bots ML, Slooter AJC, van Harskamp F, van Duijn CN, Van Broeckhoven C \& Grobbee DE (1997) Atherosclerosis, apolipoprotein E, and prevalence of dementia and Alzheimer's disease in the Rotterdam Study. Lancet 349, 151-154.

Homocysteine Lowering Trialists' Collaboration (1998) Lowering blood homocysteine with folic acid based supplements: meta-analysis of randomised trials. British Medical Journal 316 894-898.

Jama JW, Launer LJ, Witteman JCM, denBreeijen JH, Breteler MMB, Grobbee DE \& Hofman A (1996) Dietary antioxidants and cognitive function in a population-based sample of older persons: The Rotterdam study. American Journal of Epidemiology 144, 275-280.

Kalmijn S, Feskens EJM, Launer LJ \& Kromhout D (1997a) Polyunsaturated fatty acids, antioxidants, and cognitive function in very old men. American Journal of Epidemiology 145, 33-41.

Kalmijn S, Feskens EJM, Launer LJ, Stijnen T \& Kromhout D (1995) Glucose-intolerance, hyperinsulinemia and cognitive function in a general-population of elderly men. Diabetologia 38, 1096-1102.

Kalmijn S, Launer LJ, Lindemans J, Bots ML, Hofman A \& Breteler MMB (1999) Total homocysteine and cognitive decline in a community-based sample of elderly subjects: The Rotterdam Study. American Journal of Epidemiology 150, 283-289.

Kalmijn S, Launer LJ, Ott A, Witteman JCM, Hofman A \& Breteler MMB (1997b) Dietary fat intake and risk of dementia in the Rotterdam Study. Annals of Neurology 42, 776-782.

Kaplan JR, Manuck SB \& Shively CA (1991) The effects of fat and cholesterol on social behaviour in monkeys. Psychosomatic Medicine 53, 634-642.

Kaplan JR, Shively CA, Fontenot MB, Morgan TM, Howell SM, Manuck SB, Muldoon MF \& Mann JJ (1994) Demonstration of an association among dietary cholesterol, central serotonergic activity, and social behaviour in monkeys. Psychosomatic Medicine 56, 479-484.

Kinsella JE, Lokesh B \& Stone RA (1990) Dietary n-3 polyunsaturated fatty acids and amelioration of cardiovascular disease: possible mechanisms. American Journal of Clinical Nutrition 52, 1-28.

La Rue A, Koehler K, Wayne SJ, Chiulli SJ, Haaland KY \& Garry PJ (1997) Nutritional status and cognitive functioning in a normally aging sample: a 6-y reassessment. American Journal of Clinical Nutrition 65, 20-29.

Lean MEJ, Han TS, Prvan T, Richmond PR \& Avenell A (1997) Weight loss with high and low carbohydrate $1200 \mathrm{kcal}$ diets in free living women. European Journal of Clinical Nutrition 51, 243-248.

Lethem R \& Orrell M (1997) Antioxidants and dementia. Lancet 349, 1189-1190.

Linder MC (1991) Nutritional Biochemistry and Metabolism: With Clinical Applications, 2nd ed. Norwalk, CT: Appleton and Lange.

Litman BJ \& Mitchell DC (1996) A role for phospholipid polyunsaturation in modulating membrane protein function. Lipids 31, Suppl., S193-S197.

Maes M, Smith R, Christophe A, Cosyns P, Desnyder R \& Meltzer H (1996) Fatty acid composition in major depression: decreased $\omega 3$ fractions in cholesteryl esters and increased 


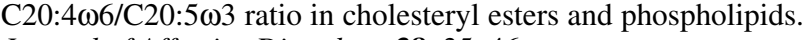
Journal of Affective Disorders 38, 35-46.

Meydani M (1998) Nutrition, immune cells, and atherosclerosis. Nutrition Reviews 56, S177-S182.

Moroney JT, Tanng MX, Berglund L, Small S, Merchant C, Bell K, Stern Y \& Mayeux R (1999) Low-density lipoprotein cholesterol and the risk of dementia with stroke. Journal of the American Medical Association 282, 254-260.

Morris MC, Beckett LA, Scherr PA, Hebert LE, Bennet DA, Field TS \& Evans DA (1998) Vitamin E and vitamin C supplement use and risk of incident Alzheimer disease. Alzheimer Disease and Associated Disorders 12, 121-126.

Muldoon MF, Barger SD, Ryan CM, Flory JD, Lehoczky JP, Matthews KA \& Manuck SB (2000) Effects of lovastatin on cognitive function and psychological well-being. American Journal of Medicine 108, 538-546.

Muldoon MF, Manuck SB \& Matthews KA (1990) Lowering cholesterol concentrations and mortality: a quantitative review of primary prevention trials. British Medical Journal 310, 309-314.

Muldoon MF, Rossouw JE, Manuck SB, Glueck CJ, Kaplan JR \& Kaufmann PG (1993) Low or lowered cholesterol and risk of death from suicide and trauma. Metabolism 42, Suppl. 1, 45-56.

Muldoon MF, Ryan CM, Matthews KA \& Manuck SB (1997) Serum cholesterol and intellectual performance. Psychosomatic Medicine 59, 382-387.

Murray CJL \& Lopez AD (1996) The Global Burden of Disease. Cambridge, MA: Harvard School of Public Health.

Ortega RM, Requejo AM, Andrés P, López-Sobaler AM, Quintas ME, Redondo MR, Navia B \& Rivas T (1997) Dietary intake and cognitive function in a group of elderly people. American Journal of Clinical Nutrition 66, 803-809.

Peet M, Murphy B, Shay J \& Horrobin D (1998) Depletion of omega-3 fatty acid levels in red blood cell membranes of depressive patients. Biological Psychiatry 43, 313-314.

Perkins AJ, Hendrie HC, Callahan CM, Gao S, Unverzagt FW, Xu Y, Hall KS \& Hui SL (1999) Association of antioxidants with memory in a multiethnic elderly sample using the Third National Health and Nutrition Examination Survey. American Journal of Epidemiology 150, 37-44.

Perrig WJ, Perrig P \& Stähelin HB (1997) The relation between antioxidants and memory performance in the old and very old. Journal of the American Geriatrics Society 45, 718-724.

Ploeckinger B, Dantendorfer K, Ulm M, Baischer W, Derfler K, Musalek M \& Dadak C (1996) Rapid decrease of serum cholesterol concentration and postpartum depression. British Medical Journal 313, 664.

Polet P, Rogers PJ, Wardle J, Atkinson EA, Vallis L, Rapoport L, Taylor M \& Judd P (1998) Mood effects of reduced-fat dietary treatment. Proceedings of the Nutrition Society 57, 83A.

Prince MJ, Bird AS, Blizard RA \& Mann AH (1996) Is the cognitive function of older patients affected by antihypertensive treatment? Results from 54 months of the Medical Research Council's treatment trial of hypertension in older adults. British Medical Journal 312, 801-805.

Prinz PN (1995) Sleep and sleep disorders in older adults. Journal of Clinical Neurophysiology 12, 139-146.

Rao R (2000) Cerebrovascular disease and later life depression: An age old association revisited. International Journal of Geriatric Psychiatry 15, 419-433.

Richardson JS (1993) Free radicals in the genesis of Alzheimer's disease. Annals of the New York Academy of Sciences 695, 73-76.

Riggs KM, Spiro A, Tucker K \& Rush D (1996) Relations of vitamin B-12, vitamin B-6, folate and homocysteine to cognitive performance in the Normative Aging Study. American Journal of Clinical Nutrition 63, 306-314.
Rogers PJ (1995) Food, mood and appetite. Nutrition Research Reviews 8, 243-269.

Rosenberg IR \& Miller JW (1992) Nutritional factors in physical and cognitive functions of elderly people. American Journal of Clinical Nutrition 55, 1237S-1243S.

Rubinsztein DC (1995) Apolipoprotein E: a review of its roles in lipoprotein metabolism, neuronal growth and repair and as a risk factor for Alzheimer's disease. Psychological Medicine 25, 223-229.

Sano M, Ernesto C, Thomas RG, Klauber MR, Schafer K, Grundman M, Woodbury P, Growden J, Cotman CW, Pfeiffer E, Schneider LS \& Thal LJ (1997) A controlled trial of selegiline, alpha-tocopherol, or both as treatment for Alzheimer's disease. The New England Journal of Medicine 336, 1216-1222.

Schmidt R, Hayn M, Reinhart B, Roob G, Schnidt H, Schumacher M, Watzinger N \& Launer LJ (1998) Plasma antioxidants and cognitive performance in middle-aged and older adults: Results of the Austrian Stroke Prevention Study. Journal of the American Geriatrics Society 46, 1407-1410.

Shaper AG, Wannamethee SG \& Walker M (1997) Body weight: implications for the prevention of coronary heart disease, stroke, and diabetes mellitus in a cohort study of middle aged men. British Medical Journal 314, 1311-1317.

Smith A, Clark R, Nutt D, Haller J, Hayward S \& Perry K (1999) Anti-oxidant vitamins and mental performance of the elderly. Human Psychopharmacology - Clinical and Experimental 14, 459-471.

Smith AP, Clark RE, Nutt DJ, Haller JG, Hayward S \& Perry K (2000) Vitamin C, mood and cognitive functioning in the elderly. Nutritional Neuroscience 2, 249-256.

Spring B, Chiodo J \& Bowen DJ (1987) Carbohydrates, tryptophan, and behavior: A methodological Review. Psychological Bulletin 102, 234-256.

Stabler SP, Lindenbaum J \& Allen RH (1997) Vitamin B-12 deficiency in the elderly: current dilemmas. American Journal of Clinical Nutrition 66, 741-749.

Stewart R (1999) Hypertension and cognitive decline. British Journal of Psychiatry 174, 286-287.

Stewart R \& Liolitsa D (1999) Type 2 diabetes mellitus, cognitive impairment and dementia. Diabetic Medicine 16, 93-112.

Stoll AL, Severus WM, Fremman MP, Rueter S, Zboyan HA, Diamond E, Cress KK \& Maraangell LB (1999) Omega 3 fatty acids in bipolar disorder: A preliminary double-blind, placebocontrolled trial. Archives of General Psychiatry 56, 407-412.

Teff KL, Young SN \& Blundell JE (1989a) The effect of protein or carbohydrate breakfasts on subsequent plasma amino acid levels, satiety and nutrient selection in normal males. Pharmacology, Biochemistry and Behavior 34, 829-837.

Teff KL, Young SN \& Marchand L \& Botez MI (1989b) Acute effect of protein or carbohydrate breakfasts on human cerebrospinal fluid monoamine precursor and metabolite levels. Journal of Neurochemistry 52, 235-241.

Thomas T, Thomas G, McLendon C, Sutton T \& Mullan M (1996) $\beta$-amyloid-mediated vasoactivity and vascular endothelial damage. Nature 380, 168-171.

Ueland PM \& Refsum H (1989) Plasma homocysteine, a risk factor for vascular disease: Plasma levels in health, disease, and drug therapy. Journal of Laboratory and Clinical Medicine 114, 473-501.

Wardle J (1995) Cholesterol and psychological well-being. Journal of Psychosomatic Research 39, 549-562.

Wardle J, Armitage J, Collins R, Wallendszus K, Keech A \& Lawson A (1996) Randomised placebo controlled trial of the effect on mood of lowering cholesterol concentration. British Medical Journal 313, 75-78.

Wardle J, Rogers PJ, Judd P, Taylor MA, Rapoport L, Green MW \& Nicholson-Perry K (2000) Randomized trial of the effects of 
cholesterol-lowering dietary treatment on psychological function. American Journal of Medicine 108, 547-553.

Witztum JL (1994) The oxidation hypothesis of atherosclerosis. Lancet 344, 793-795.

Wurtman RJ, Hefti F \& Melamed E (1981) Precursor control of neurotransmitter synthesis. Pharmacological Reviews 32, $315-335$.
Wurtman RJ \& Wurtman JJ (1989) Carbohydrates and depression. Scientific American 260, 50-57.

Young SN (1993) The use of diet and dietary components in the study of factors controlling affect in humans: A review. Journal of Psychiatry and Neuroscience 18, 235-244. 